Western University Scholarship@Western

Political Economy Research Group. Papers in

Political Economy

Economics Working Papers Archive

1991

\title{
Can Repressive Regimes be Moderated Through Foreign Aid?
}

Filip Palda

Follow this and additional works at: https://ir.lib.uwo.ca/economicsperg_ppe

Part of the Economics Commons

Citation of this paper:

Palda, Filip. "Can Repressive Regimes be Moderated Through Foreign Aid?." Political Economy Research Group. Papers in Political Economy, 15. London, ON: Department of Economics, University of Western Ontario (1991). 
POLITICAL

ECONOMY

RESEARCH

GROUP

\section{PAPERS IN POLITICAL ECONOMY}

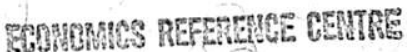

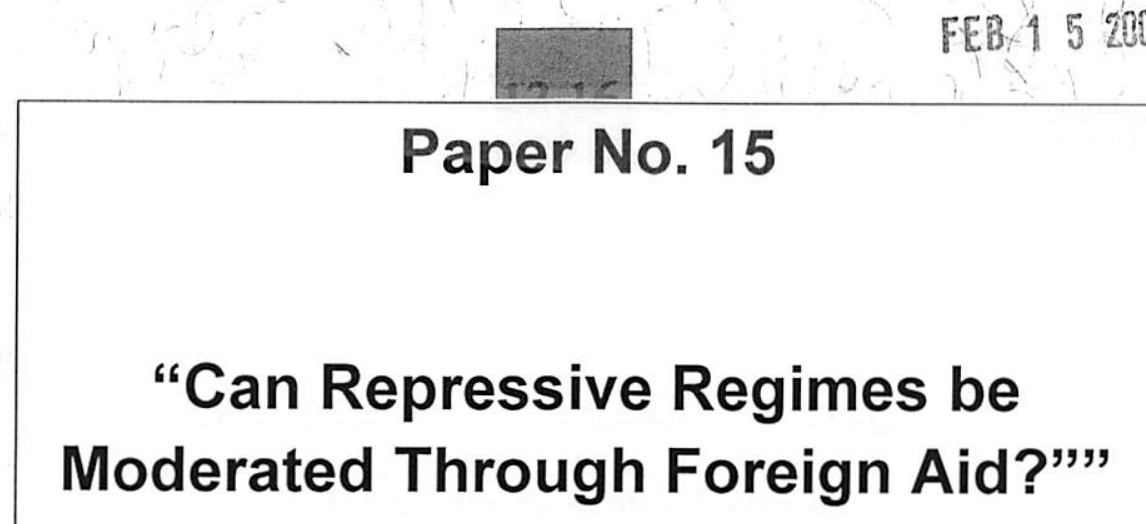

Filip Palda

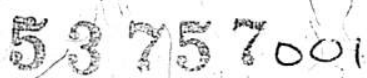

5. 15001

5359001

56 600 
The Political Economy Research Group was established in the faculty of Social Science at the University of Western Ontario in 1988. Its purpose is to foster scholarship, teaching and interdisciplinary research in political economy, with a focus on:

1. the ápplication of economic models and methods to the study of political processes and institutions,

2. the economic impact of political processes and institutions,

3. the influence of economic factors on the formation of public policy and on institutional change,

4. the politics of economic policy making,

5. the political, social, and economic effects of public policy.

Co-directors:

Ronald Wintrobe (Economics);

Robert Young (Political Science)

Board of Directors:

Peter Howitt (Economics)

B.B. Kymlicka (Political Science)

John N. McDougall (Political Science)

Peter Neary (History)

John Whalley'(Economics)

Staff:

Jayne Dewar

3

For further information:

Political Economy Research Group,

Department of Economics,

Social Science Centre,

London, Ontarió, Canada N6A.5C2

phone: (519) 661-3877

fax: (519) 661-3292 


\title{
Can Repressive Regimes be Moderated Through Foreign Aid? *
}

\author{
Filip Palda \\ University of Ottawa \\ October 1989 \\ REVISED: January 1990
}

\begin{abstract}
How should foreign aid be given to repressive, less developed countries? Repressive rulers are assumed to control the national income and to trade it against the probability of staying in office which is assumed to depend positively on popular wealth and repression. A foreign donor aware of this process of optimization will pursue his international objectives by attaching conditions to his aid that alter the relative price of repression and popular wealth in the calculations of the tyrant. The effectiveness of aid and the desirability of a "carrot and stick" aid policy depend on the direct and on the interactive effects that popular wealth and repression exert on the regime's stability. The importance of gifts in kind such as food and arms is questioned and the value of data on repression used to formulate aid policy is assessed.
\end{abstract}

"I would like to thank Hugo Juan-Ramon, John Matsusaka, and Ian Parry for their kind advice and Janice Coen for her proofreading. 


\section{Introduction}

The economic progress of less developed countries (LDC's) and the rights and the liberties of their populations are matters that occupy an important place in the agendas of wealthy nations. Since the decline of gunboat diplomacy, the United States, Britain, France, and recently Japan, have influenced the economies and political systems of developing countries by lending and by giving money, through gifts in kind, and by imposing sanctions. The Marshall plan was an early and successful example of the economic remote control that today is most visibly exerted by the International Monetary Fund and the World Bank. A theme in the policies of such institutions is that economic assistance should be given with concern not only for the growth of the recipient but also for the manner in which the fruits of that growth are distributed among the inhabitants. Policy makers do not send help to South Africa, Chile, and Viet Nam because they fear that few but the rulers will benefit. However when countries with dark records promise to mend their ways, as many in the East Bloc have recently done, policy makers are quick to open their purses. The fluctuations in American foreign economic assistance by region that appear in Figure 1 stem in part from the reactions of Carter and Reagan to trends in the abuse of human rights (McGuire and Ruttan 1989).

This paper examines what may happen to the welfare of the rulers and of the ruled in a repressive, less developed country when national income changes and uses the results to ask what the consequences of foreign aid will be. The principles of aid are derived from two ingredients. First, a model is built of the uses to which recipient countries put their aid. It is assumed that rulers may pocket some part, give some part to their people and spend some part on repression of their people. The resulting behavioural equations are shown to constrain foreign donors in their pursuit of national objectives. These constraints guide the donors in their aid to repressed LDC's. What the model predicts about repression and income distribution may be applied to a country at any stage of development, but LDC's are the focus of the discussion because in practice they are the main beneficiaries of foreign aid.

This is not an essay on how to launch economic development. The factors that. drive income are taken as given and are not studied. The object is to explain how 
rugure 1: American foreign aud (in billions of 1982 dollars) by reg ion for vie period 1976-1988.

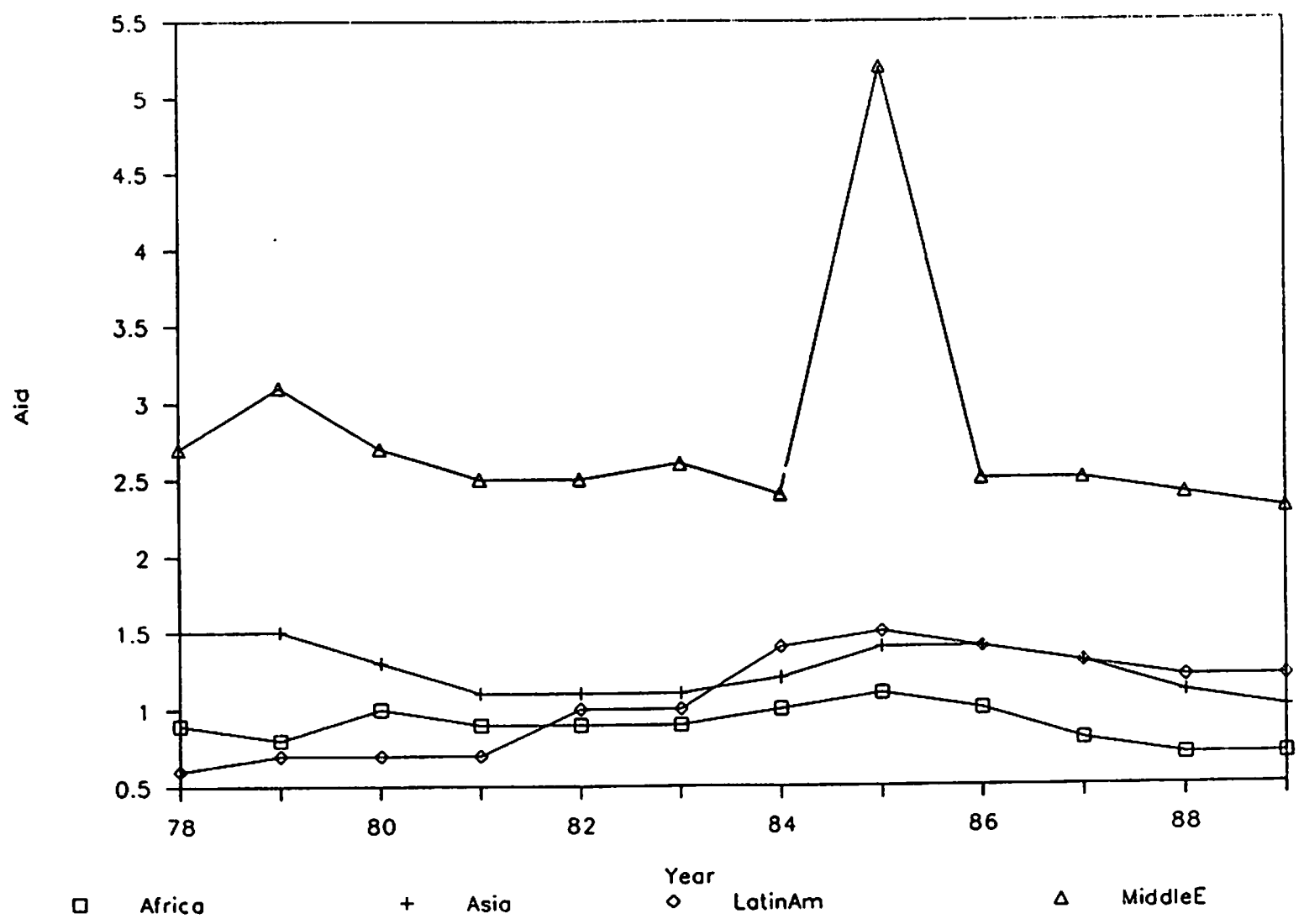

Fig ure 2: American foreign aid (in billions of 1982 dollars) by type for the Deriod 1976-1988.

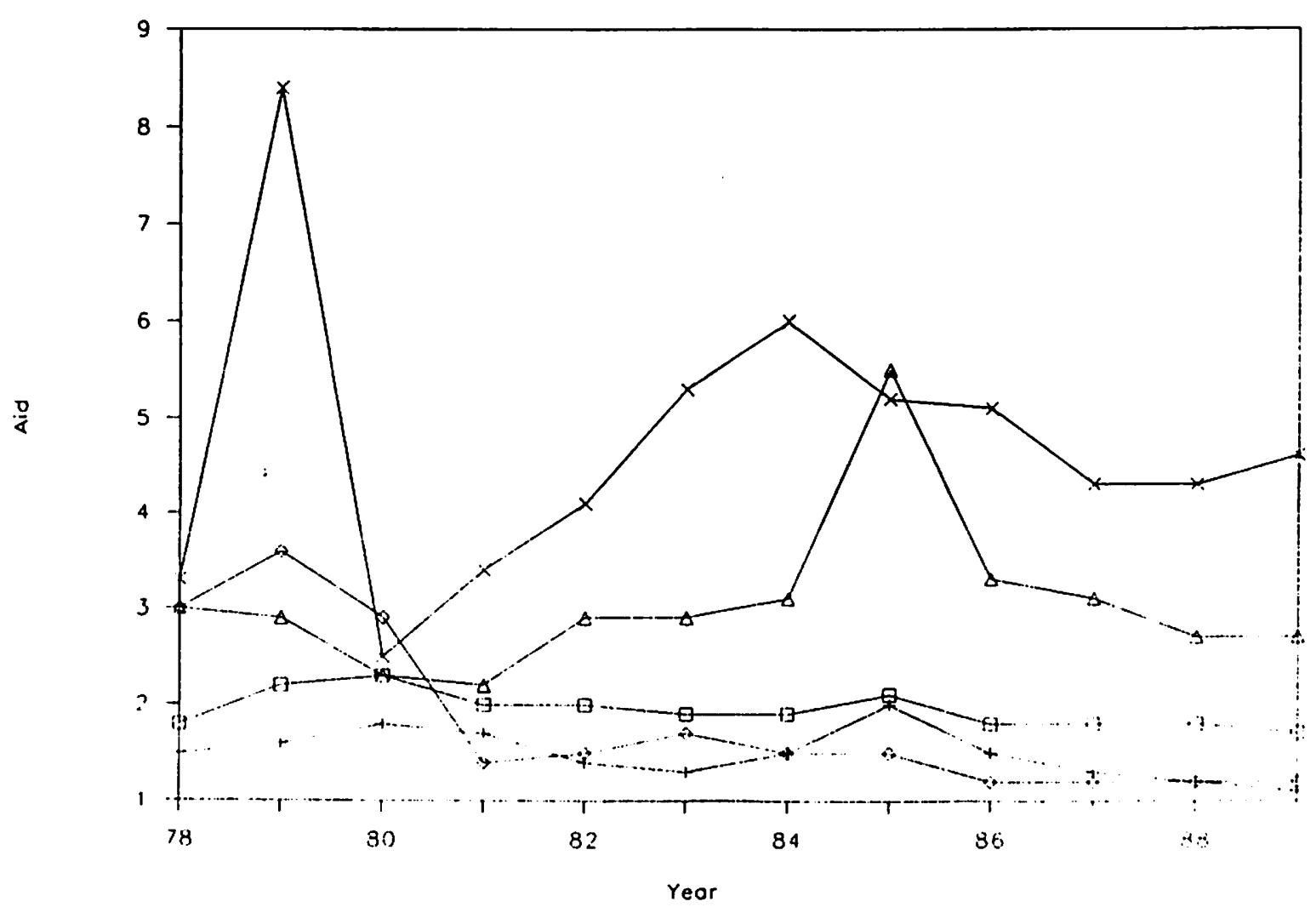


a policy of foreign economic aid may affect both the distribution of wealth and the level of repression in a developing country. The proposed theory shows that even with vast resources and varied instruments, a donor may not be able to lower repression and at the same time change the distribution of income in an equitable manner. For if aid is to be effective it must be accepted by the oppressive ruler. He will accept aid only if it raises his utility-an unsavoury proposition that is seldom mentioned. This cramps the donor's ability to attach conditions to his gift.

The word "condition" is used here in a qualified sense. The donor may offer a fixed sum every year, from which he subtracts proportionately to the recipient's outlays on repression and to which he adds proportionately to the expenditures for the benefit of the people. The amounts added or subtracted are the conditions attached. The fixed sum and the conditions attached are the "aid package". An aid package works by changing the budget constraints of the rulers who control a country's wealth and who may spend that wealth on themselves, on the people or on repressing the people. Reasoning in this way alerts one to the great fallacy of established aid policy: that gifts in kind will go in full to their intended recipients. Plots in Figure 2 of American aid by type (food, military, development assistance, cash) over the past twelve years suggest that finding an appropriate mix of aid has captivated policymakers. The present paper warns that in all likelihood a gift in kind such as food, frees resources once devoted to agriculture, to use by the repressive ruler. An intelligent package of aid will try to influence the rate at which resources may be transformed from one use to another.

Section 2 models income distribution in a repressive regime. Section 3uses this model to inquire how foreign aid will change repression and the wealth of rulers and ruled. Section 4 explains the optimal plan of foreign aid that. donors should follow to further humanitarian objectives. The influence of growth on repression is given special attention and is contrasted to a recent line of research which emphasizes the reverse, namely, the influence of repression on growth. The importance of regression estimates of the parameters of both of these models to the practical assembly of an aid package is also evaluated. This matter is taken up in section 5 . 


\section{Income Distribution in a Repressive State}

A distinguishing feature of undemocratic regimes is tight central control over national income. The present model assumes that an absolute government is one with complete discretion in the use of the national income of $Y$. Members of the government may divide $Y$ between themselves, $G$, the people, $P$, and they may spend part of it on repression $R$. This suggests the national income identity:

$$
Y=G+P+R
$$

Repression ceteris paribus increases the probability, $\pi$, that the government will stay in power long enough to benefit from resources $G$. That probability is also assumed to increase with the wealth of the people $P$. Hence:

$$
\pi=\pi(\underbrace{R}_{+}, \underbrace{P}_{+})
$$

Such a function can be derived from the intertemporal analysis of an economy in which the oppressed citizenry must at every instant weigh the present expected value of seizing power to gain control over $Y$ against the costs of a failed coup (Roemer 1985, Parry 1989). For the task at hand it suffices to assume the existence of such a function and to ascribe to it certain reasonable properties.

Assume that the government's objective is to maximize its expected wealth subject to the national income constraint. ${ }^{1}$ The government manipulates $P, G$, and $R$ to maximize the Lagrangean:

$$
\mathcal{L}=\pi(R, P) G+\lambda(Y-G-P-R)
$$

If dictators really do maximize $\pi \times G$ then there is much evidence to support the assumption that $\pi_{R}, \pi_{P}>0$. Dictators are widely observed to repress their people and to live well at their expense but they never rob them of everything. Repression comes at a cost to the dictator and he derives no direct pleasure from it. Its only function is to keep him in power. If repression loosened the grip on power $\left(\pi_{R}<0\right)$

\footnotetext{
${ }^{1}$ Parallel approaches to income distribution have been taken by by Usher and Engineer (1987), Wintrobe (1989) and Palda (1989).
} 
then dictators the world over would put away their bullwhips and minister to the downtrodden. Similarly, if stability rose as the people starved $\left(\pi_{P}<0\right)$ dictators would expropriate to the point where $\pi_{P}$ became positive. This loose proof is the same as the one made to show why individuals consume goods of which more is preferred to less (Becker 1970). The multiplier $\lambda$ is the expected utility the ruler gets from an extra dollar of national income. The first order conditions yield the following restrictions:

$$
\pi_{P} G=\pi_{R} G=\pi
$$

The marginal benefit of increasing government's share of $Y$ is $\pi$ and it is equated to the marginal benefits of an additional unit of $P$ and $R$. Each of $P, G$ and $R$ can be solved for in terms of $Y$ and substituted back in the first order conditions. The resultant comparative statics are summarized below:

$$
\begin{gathered}
R_{Y}=\frac{G \pi_{P}}{\Delta}\left(\pi_{P P}-\pi_{P R}\right) \\
P_{Y}=\frac{G \pi_{P}}{\Delta}\left(\pi_{R R}-\pi_{P R}\right) \\
G_{Y}=1-\frac{G \pi_{P}}{\Delta}\left(\pi_{R R}+\pi_{P P}-2 \pi_{P R}\right)
\end{gathered}
$$

where $\Delta$ is the determinant of the bordered Hessian derived from the second order conditions. It is negative. In this setup income is the catalyst of all change-an extreme simplification but one which seems to agree with the historical record that political behaviour is influenced by the level of national income (McNeill 1958). Changes in national income will influence among other variables, the level of repression $R$. This is worth noting because recent regressions (Friedman 1988, Glahe and Vorhies 1989) of national income on Gastil's index of repression (Gastil 1980) have sought to demonstrate the reverse: namely that economic growth may depend on political structure. The present model suggests that income can grow exogenously and still bear a strong relation to repression. ${ }^{2}$ Section 5 takes up this point in greater detail.

\footnotetext{
${ }^{2}$ Suppose economic growth is affected by political freedom. To see that the quality of results does not change assume that

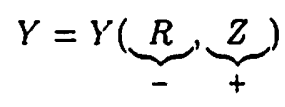


The second order conditions do not restrict the signs of $\pi_{P P}, \pi_{R R}$, and $\pi_{P R}$, but throughout it is assumed that $\pi_{P P}$ and $\pi_{R R}$ are negative. That is, there are diminishing returns to investing in repression and to giving wealth to the people. The formula for $R_{Y}$ indicates that repression will tend to rise with a rise in income if the returns to giving wealth to the people diminish rapidly. Similarly the more negative is $\pi_{R R}$ the greater will $P_{Y}$ tend to be. Diminishing returns in $P$ and $R$ also tend to increase the amount of a rise in $Y$ a government takes for itself.

The final influence on $P, R$ and $G$ of a change in national income depends on the sign of the cross derivative of the probability a regime will last, with respect to the amounts spent on repression and on the people, $\pi_{P R}$. Suppose that $\pi_{P R}>0$. This states that the productivity of repression rises with the wealth of the people. To put it differently, repression will have little effect on a poor population. Such might be the case when poverty unites the people in a common revolutionary cause in which there is little incentive to free ride. The result of $\pi_{P R}$ being positive is that $R_{Y}>0$ and $P_{Y}>0$. Repression and popular income are, loosely speaking, normal goods in the calculations of rulers. A rise in income will lead to more income for the people but they will be more repressed. However the sign of $G_{Y}$ is ambiguous.

Poland was a country which until recently resembled this case. Its feeble economy had by the early months of 1989 curbed the repressive tendencies of the communist party. These tendencies were very much in evidence in the relatively more

where $Z$ are some exogenous driving forces in the economy. Assume that $Y_{R R}<0$ (i.e. there are increasing costs to increasing repression). Substituting this in the budget constraint, the first order condition on a change in $R$ becomes:

$$
\mathcal{L}_{R}=\pi_{R} G+\lambda\left(Y_{R}-1\right)=0
$$

Comparative statics are now conducted with respect to changes in $Z$. Some rough idea of these comparative statics can come from the marginal rate of substitution between $P$ and $R$ implied by the first order conditions:

$$
M R S_{P, R}=\frac{\pi_{P}}{\pi_{R}}=\frac{1}{1-Y_{R}}
$$

Recall that $Y_{R}<0$. The higher is $-Y_{R}$ the smaller will be the ratio of $\pi_{P}$ to $\pi_{R}$. Now repression carries an added cost: ceteris paribus it reduces national income at an increasing rate. If repression also reduces the marginal influence of $Z$ on $Y$ then this will be an added cost which mitigates investment in $R$. 
prosperous Gomulka and early Jaruzelski regimes. Economic aid to Poland given in the 60's and 70's may actually have weakened the forces of reform if in fact repression there was a normal good $\left(R_{Y}>0\right)$.

Some may prefer to think of $\pi_{P R}$ as being negative because as people grow wealthier they can afford the type of liberal education which brings them to recognize the extent of their submission. When $\pi_{P R}<0$ a rise in $Y$ will tend to diminish repression the more negative is $\pi_{P R}$ (this is not to say that repressions will not increase). Similarly, a more negative $\pi_{P R}$ will tend to diminish the share of a rise in $Y$ that the people receive because it decreases the productivity of repression. Finally, $G$ will tend to rise with $Y$ as $\pi_{P R}$ diminishes. If the returns to giving to the people diminish more rapidly than the returns to repression we may well observe that as income grows repression fades $\left(R_{Y}<0\right)$, and that popular income and the wealth of rulers grow $\left(P_{Y}>0\right.$, and $\left.G_{Y}>0\right)$.

France and Russia in the days before their revolutions are examples of countries which experienced rapid economic growth, increasing popular wealth $\left(P_{Y}>0\right)$, liberalization $\left(R_{Y}<0\right)$ and growing government opulence $\left(G_{Y}>0\right)$. Revolution might have come to these countries because those ruling were willing to trade a rise in wealth for a fall in their probability of holding on to power. The equilibrium change in $\pi$ would have been:

$$
\pi_{Y}=\underbrace{\pi_{P} P_{Y}}_{+}+\underbrace{\pi_{R} R_{Y}}_{-}
$$

and with a rapid decrease in repression $\pi$ could have decreased. A similar force may be at work in South and Central America where dictators risk their positions in order to plunder the public coffers. The flight of the treasure-laden Marcos from the Philippines is another example of what may have been a choice between stability and wealth, made by a repressive leader.

\section{The Role of Aid}

The model just deweloped can show that foreign aid may affect not only the level of wealth in a represcive regime, but also its distribution between rulers, ruled and the resources turned :o repression. The final effect will depend on the conditions 
attached to the aid and on the properties of the probability function $\pi$. Aid should be portrayed realistically and in a way that fits neatly in the framework of income distribution built in the last section. Consider the case of a repressive regime which receives help from a single donor in the following form:

$$
A=F+\beta P-\alpha R
$$

where

$A$ is the sum of money given by the donor.

$F$ is a fixed component of aid.

$\beta P$ is the component of aid which depends on the wealth of the people $(\beta>0)$. Many world bank and IMF loans are given on condition that the private economy be developed. Repressive governments may win favour (through a mechanism such as $\beta$ ) by allowing free enterprise (large $P$ to flourish).

$\alpha R$ is the component of aid which depends on the sum spent on repression ( $\alpha>$ $0)$. The Carter administration (1977-81) may have acted with something like $\alpha$ in mind when it banned military training funds for Argentina, Uruguay and Ethiopia; and stopped all aid to Angola, Cambodia and Laos because repression had grown in those parts.

In this stylized setting, the donor sets $F, \alpha$, and $\beta$ to arrive at a sum of aid $A$. In practice the U.S. gives aid through agencies for development assistance, food, and military training; through the Economic Support Fund, and with reluctance through multilateral agencies such as the World Bank, the IMF and UNICEF. In practice the instruments $\alpha, \beta$ and $F$ may each be put to work through separate agencies. For example, the Reagan administration used the Economic Support Fund for cash transfers that were relatively free of restriction (McGuire and Ruttan 1989). In the context of the present model, spending by the Economic Support Fund might be thought of as $F$. The president also relied on USAID reports to set conditions (such as $\alpha$ and $\beta$ ) on food and development aid.

In this framework national wealth may be expressed as:

$$
Y+F=(1+\alpha) R+(1-\beta) P+G
$$




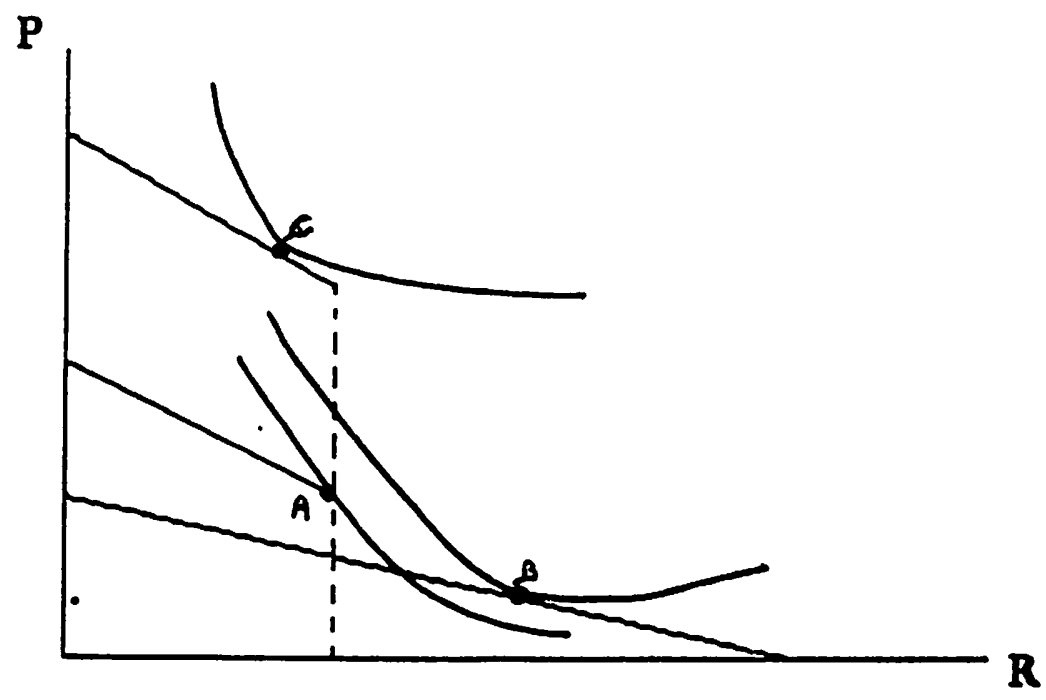

Figure 3: The higher is the fixed component of aid (topmost budget-line) the greater is the chance it will be accepted.

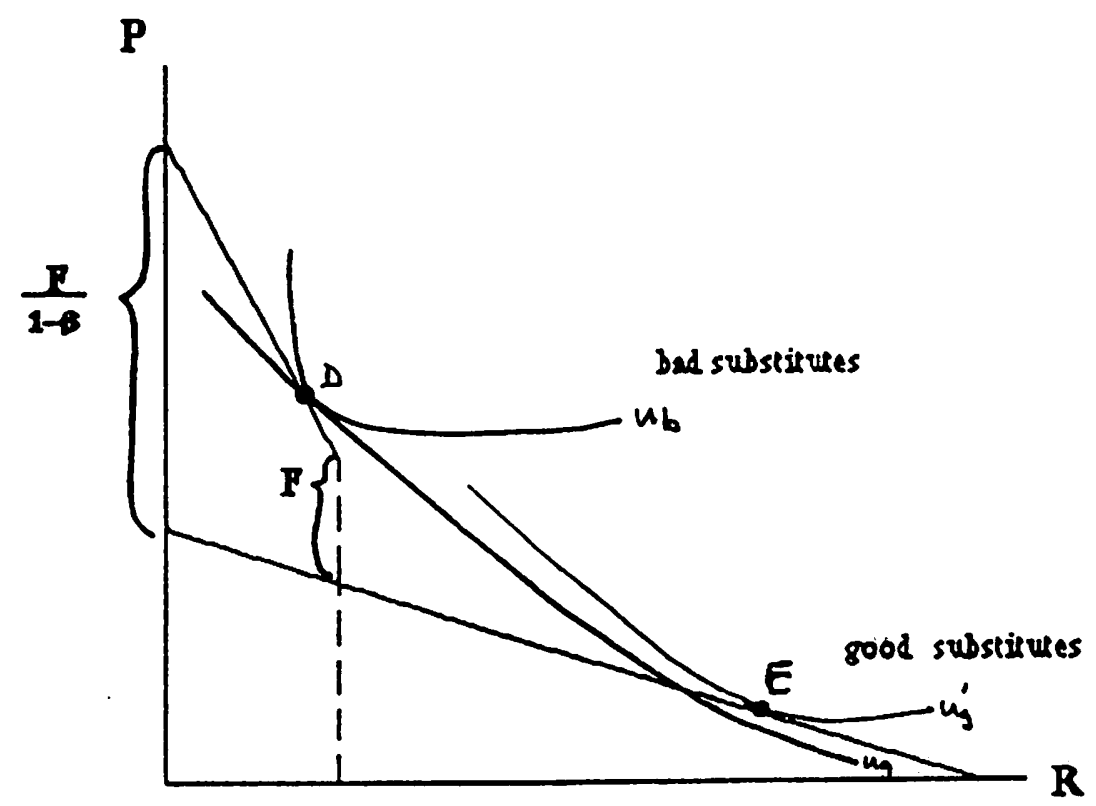

Figure 4: Aid is more likely to be accepted by the repressive ruler if repression and popular wealth are bad subsitutes in his calculations. 
The rate at which $R$ and $P$ can be substituted by the repressive rulers is influenced by the ratio of $1+\alpha$ to $1-\beta$. The higher the ratio, the higher is the price of repression in terms of popular wealth. ${ }^{3}$ Now if rulers maximize their expected wealth $\pi(R, P) G$ w.r.t. the new national income constraint (2), the f.o.c.'s imply that:

$$
\frac{\pi_{R}}{\pi_{P}}=\frac{1+\alpha}{1-\beta}
$$

The left-hand-side is the marginal rate of substitution between $R$ and $P$ which in equilibrium must be equal to the ratio of their prices. This equilibrium may not be unique because foreign aid puts a kink in the national income constraint. The possibility of more than one equilibrium here means simply that the repressive ruler may not accept a package of aid to which severe conditions (high $\alpha$ ) are attached.

Two corollaries, illustrated in Figure 3 and 4 , are that given any set of conditions defined by the donor ( $\alpha$, and $\beta$ ), a package of aid is more likely to be accepted if the fixed component $F$ is high (Figure 3 , in which point $B$, where aid is not accepted, is preferred to the low level of aid at $A$; When the fixed component is high enough aid may be accepted at a point like $C$ ) or if repression and popular wealth are bad substitutes in the calculations of rulers (Figure 4, where the no aid point $D$ is preferred to the aid point $E$ by the dictator when $P$ and $R$ are good substitutes). 4 The second corrolary is not encouraging because when $P$ and $R$ are bad substitutes changes in the slope of the budget line that come from changes in the aid condition will have little effect. Figure 1 also makes the obvious, but important point that no repressive ruler will accept aid if it does not increase his own utility. As Lenin, who was adept at calculating where the interests of his party

\footnotetext{
${ }^{3}$ This is true only if the foreign aid constraint(1) is binding. If $R$ is too great no aid will be given and $\alpha$ and $\beta$ do not influence the ruler's decisions. The critical $R$ past which (1) does not bind is:

$$
\begin{aligned}
F+\beta P-\alpha R & \leq 0 \Rightarrow \\
R & \geq \frac{F+\beta P}{\alpha}
\end{aligned}
$$

The higher $\alpha$, i.e. the greater the penalty the donor places on repression, the lower will the critical $R$ be. See also Figure 1

${ }^{4}$ This is likely when $P$ and $R$ work together to increase the stability of a regime, for in such a case the ruler will benefit on two counts $\left(\pi_{P}>0\right.$ and $\left.\pi_{P R}>0\right)$ from passing part of the aid on to his subjects.
} 
lay, remarked "Please add my vote to those in favour of accepting food and weapons from the Anglo-French imperialist robbers" (DeJong 1986). Thus if our method is to give money to better the lot of the disenfranchised citizens of China, we must first appeal to the interests of those who control events from the Forbidden City and of their accomplices who wield truncheons in the street. As the first-order conditions (3) suggest, a clever appeal to their interests will be one which manipulates $\alpha, \beta$, and $F$ in a way that lowers repression and increases popular wealth. Perhaps it was ignorance of this vital message carried in the first-order conditions that led to some of the spectacular failures of Western aid, such as those "...which enabled Dr. Nyerere [of Tanzania] to continue for so long with forcible collectivization" and which "... enabled Obote of Uganda in 1966 to destroy the widely popular Kabaka and to establish his dictatorship" (Bauer 1988). To quote McGuire and Ruttan (1989): "If any [American] policy could be classified as lacking design, the Africa policy would be it."

The international effort to undo the man-made famine of 1985 in Ethiopia is a compelling example of vast material help ( $F$ large) given with almost no conditions attached ( $\alpha$ and $\beta$ small). One need only examine the national income identity (2) to see that a gift in kind such as food, intended for the people but administered by the ruler, is very close to a deposit placed in his private bank account. The gift of food frees resources which the dictator may divide between himself, repression, and the people. Thus it should have come as no surprise that as it took delivery of grain (which America and others gave without condition) the Ethiopian Relief and Rehabilitation Commission should sell a ton of high quality feta cheese sent by the Bulgarians, for hard currency to the diplomatic community of Addis Ababa (Korn 1986). The massive Western delivery of grain also allowed Mengistu's dictatorship to divert almost all the government's resources from the starving, to its pet project of resettling able-bodied men from the troublesome north-central highlands to other parts where rebels could not recruit them. According to the American Charge d'Affairs at the time

The West did famine relief while the Ethiopian government did resettlement ... Because the Ethiopian regime devoted almost all of its resources to resettlement it had very little to offer for famine relief (Korn 
1986).

The international aid, given in the naive belief that food can have but one use, must have been a boon to the dictatorship but of less certain benefit to the starving inhabitants of the land.

In order to examine the effect of aid on repression and popular wealth in greater detail, all discussion here will assume an equilibrium of the sort at point A in Figure 4 where the foreign aid constraint is binding. What has changed from the previous section is that now, in addition to national income, the elements of aid $F, \alpha$, and $\beta$ are parameters in the choice functions of rulers. As in standard price theory, the effects on $P, R$, and $G$ of changes in their prices can be broken into income and substitution effects. Consider the effect of a change in $1+\alpha$, the price of repression, on $R$ and $P$. Comparative statics (see Appendix) reveal that

$$
\begin{aligned}
R_{1+\alpha} & =R_{1+\alpha}^{c}-R \times R_{Y+F} \\
& =\frac{\lambda}{\Delta}\left[2 \pi_{P}(1-\beta)-\pi_{P P} G\right]-R \frac{\pi_{R} G}{\Delta}\left[\pi_{P P}-\pi_{R P}\left(\frac{1-\beta}{1+\alpha}\right)\right]
\end{aligned}
$$

and

$$
\begin{aligned}
P_{1+\alpha} & =P_{1+\alpha}^{c}-R \times P_{Y+F} \\
& =\frac{\lambda}{\Delta}\left[\pi_{P R} G-2 \pi_{P}(1+\alpha)\right]-R \frac{\pi_{P} G}{\Delta}\left[\pi_{R R}-\pi_{R P}\left(\frac{1+\alpha}{1-\beta}\right)\right]
\end{aligned}
$$

where $\lambda$ is the Lagrange multiplier and $\Delta$ the determinant of the bordered Hessian of the second order conditions. In equation (4) the own price effect of a change in $\alpha$ on repression $\left(R_{1+\alpha}\right)$ is expressed as the sum of substitution $\left(R_{1+\alpha}^{c}\right)$ and income $\left(R_{Y+F}\right)$ effects. Equation (5) does the same for the effect of $1+\alpha$ on $P$.

The substitution effect $R_{1+\alpha}^{c}$ is unambiguously negative and is larger the more rapidly returns to repression diminish (i.e. the more negative is $\pi_{P P}$ ). Furthermore, if $\pi_{P R}>0$, then both $R$ and $P$ are normal so that the income effect works unambiguously with the own substitution effect (a case studied in the previous section). The result is that repression will fall if its price $(1+\alpha)$ increases within a range that keeps the aid constraint binding. But what happens to popular wealth $P$ ? If $P$ is a gross substitute for $R\left(P_{1+\alpha}>0\right)$, then popular wealth will rise. Unfortunately, 
if $\pi_{P R}>0, P$ and $R$ will tend to be gross complements-as inspection of equation (5) suggests.

This case shows that under plausible assumptions about normality and complementarity, raising the price of repression might lower $R$, but might also lower $P$ (by the cross-price effect). In riposte the fixed component of aid $(F)$ could be increased in order to increase $P$, but because $R$ is normal, $R$ would also increase. To reduce repression and to increase popular wealth, $\alpha$ and $F$ would have to change within the following implicit bounds (see Appendix)

$$
-\frac{P_{1+\alpha}}{P_{Y+F}}<\frac{d F}{d \alpha}<-\frac{R_{1+\alpha}}{R_{Y+F}}
$$

and it is not clear that such a combination of $d \alpha$ and $d F$ can be found. The point is that donors may not be able to pursue more than one objective. If they reduce repression they might forfeit the chance to increase popular wealth. Put differently, the direction and size of income and substitution effects, more than the number of instruments (such as $\alpha$ and $F$ ), determine the goals that are within the donor's reach, and the methods best applied to their attainment. ${ }^{5}$

This discussion can be recast in the vernacular of "carrot and stick". The fixed component of aid $F$ is the carrot which tempts, and the price attached to repression (or symmetrically the subsidy attached to popular wealth $1-\beta$ ) is the stick which punishes. When $R$ and $P$ are both normal and are gross complements, carrot and stick will not work in harmony. As indicated, if $\alpha$ rises $R$ will fall, but so will $P$ (cross-price effect). Increasing $F$ will increase $P$ but will also increase $R$ (pure income effect). If the opposition of carrot to stick is not perfect, $\alpha$ and $F$ may be assiduously chosen by the donor to lower repression and to increase popular wealth. In fact the use of carrot and stick is perhaps best warranted in precisely these contrary circumstances.

On the other hand, if the fixed component of aid works in the same direction as the price attached to repression, and if both are equally costly means to the donor, only the most efficient of these two instruments should be used. For example, if $R$ is inferior and $P$ is normal, and if $R$ and $P$ are gross substitutes (a combination of

\footnotetext{
${ }^{5}$ Similar comments apply to the analysis of a change in the price of giving money to the people, $1-; 3$.
} 
effects which can exist only if repression and popular wealth have a negative cross effect on stability- $\pi_{P R}<0$ ), a large carrot will reduce repression and better the lot of the people. Economic sanctions tied to the level of repression (a variant of $\alpha$ ) will have the same effect. The astute donor will eschew the teamed use of carrot and stick in favour of the least expensive method. ${ }^{6}$

To summarize, reflections about the power of foreign aid stand or fall on the signs and magnitudes of $\pi_{P}, \pi_{R}, \pi_{P P}, \pi_{P R}$ and especially on $\pi_{P R}$. Such knowledge may help to advance subtle goals of foreign policy and it is to a closer examination of these goals that this paper now turns.

\section{Choosing a Policy of Aid}

The goals of the donor country will determine its supply of aid $(F)$ and the conditions on which receipt is conditioned $(\alpha$, and $\beta)$. In their pioneering study, Dudley and Montmarquette (1976) modelled the supply of the fixed component of aid $(F)$ by a donor whose utility function counted among other factors, the welfare of the recipients (of which they assumed a unique class, not divided as here into rulers and ruled). They tested and found that a target country's population, previous ties with the donor, and the costs of administering a gift all influenced supply. ${ }^{7}$ However, they left to others the task of explicitly modelling the demand for aidthat is, the reaction functions $R(F+Y, \alpha, \beta)$ and $P(F+Y, \alpha, \beta)$-and demand's bearing on the donor country's optimal course of action (its choice of $F, \alpha$, and $\beta$ ). The present study proposes a particular objective for the donor and confines itself to asking how he should behave.

Consider first the donor who devotes $\$ A$ to a single country for the purpose of reducing repression there and of increasing its popular wealth. Ignoring the possibility raised earlier that it may be efficient to use only one instrument, assume the donor chooses $\alpha, \beta$, and $F$ to maximize:

$$
U(P, R)+\lambda(A+\alpha R-\beta P-F)
$$

\footnotetext{
${ }^{6}$ 'This ignores marginalist cost minimizing arguments in favour of using both instruments that could be made if $F$ and $\alpha$ had different, increasing marginal costs to the donor.

${ }^{7} \mathrm{~A}$ more recent investigation along similar lines is that of Weck-Hannemann and Schneider (1988). They also provide an extensive survey of past efforts to understanding the aid decision.
} 
where $U$ is the donor's utility function which increases in $P$ and decreases in $R$ and where $R=R(\alpha, \beta, F)$ and $P=P(\alpha, \beta, F)$. The foc for $\alpha$ is:

$$
\frac{1}{\lambda}\left(U_{P} P_{\alpha}+U_{R} R_{\alpha}\right)=-R-\alpha R_{\alpha}+\beta P_{\alpha}
$$

The l.h.s. is the marginal utility in dollars of a change in $\alpha$. The r.h.s. is the marginal cost. By the 1.h.s., if punishment curbs repression $\left(R_{\alpha}<0\right)$ and increases popular wealth $\left(P_{\alpha}>0\right)$, then raising $\alpha$ raises the donor's utility. At a maximum the costs (given by the r.h.s.) must also rise. The rise will come from the increase in popular wealth (the $\beta P_{\alpha}$ term which is the extra aid that must be committed) and from the fall in $R$ (which likewise raises the aid bill), a fall which tends to increase costs. The direct effect on cost of a rise in $\alpha$ is $-R$ which is negative. The point of interest is that one cannot say a priori whether a potent instrument $\left(R_{\alpha}\right.$ large) merits broad use. A more potent $\alpha$ increases marginal utility but it also increases marginal cost. The penalty $(\alpha)$ imposed on repression may have to be softened if its deterrent effect and its promotion of popular wealth grow in a manner that increases costs more rapidly than utility. In other words, one need only whisper threats to the timid. This does not imply that $\alpha$ 's share of costs in the aid budget $\$$ A diminishes. A mild but potent condition (low $\alpha$, high $R$ ) may contribute greatly to the final amount of aid ultimately sent.

In practice the donor will have to divide his aid between many recipient countries. While the first-order conditions for this problem have much to say, this section will confine itself to asking if the aid budget can be set in two stages. To motivate the problem consider the specific case of the donor whose utility rises in the chance a repressive regime will not survive, $1-\pi$. If the donor has a global outlook he may wish to see repressive regimes the world over topple. This could be expressed in his utility function as:

$$
U_{\text {donor }}=U\left(1-\pi_{1}, 1-\pi_{2}, \ldots, 1-\pi_{n}\right)
$$

where $\pi_{i}$ is the probability applicable to recipient country $i$. He must decide how to divide his foreign aid budget between many countries and what conditions to attach. The donor who is able to make his calculations in separate stages may allow himself a certain easy style of administration: first decide how the aid budget is to be divided between many needy countries. Then, at a more detailed level of 
budgeting, and at the administrator's leisure, work out the optimal conditions $\alpha$ and $\beta$ to tie to each country's receipt of aid. McGuire and Ruttan (1989) present evidence that the budget process works in two-stages:

...the issues of how much to allocate and to whom are largely political and vary little...what varies.... is the issue of how the foreign assistance will be used by recipients.

Washington sends programming guidelines to U.S. field missions of USAID and embassy staff who return specific proposals for the conditions that should be attached to a set budget of aid.

The most important decisions-how much?and to whom?-in foreign asisstance do not involve USAID personnel; they deal only with the substantive questions of how to use assistance after it is appropriated (my italics)

These procedures are sound if drawn from optimizing conditions which indicate that two-stage budgeting is feasible. Gorman (1959) showed that two-stage budgeting is the product of rare circumstances. Can we expect these circumstances in the present model? Weak-separability of subutility functions (in this case $1-\pi_{i}\left[R_{i}, P_{i}\right]$ ), which is a necessary and sufficient condition for the second stage, seems in the present context a reasonable assumption for most countries. To paraphrase Deaton and Muellbauer (1980): if any country's level of repression and popular wealth appear only in separable subutility functions then the optimal levels of $R$ and $P$ for that country can be written as a function of the aid and of the prices of affecting $R$ and $P$, in that country alone. There is no reason to believe that repression and popular wealth in Uganda should affect the marginal rates of tranformation of these variables in the stability of Chile. As to the first stage, to continue paraphrasing, the broad group allocation problem is solved by maximizing (6) subject to the budget constraint:

$$
\sum_{i=1}^{N} A_{i}\left(1-\pi_{i}, S_{i}^{R}, S_{i}^{P}\right)=A
$$

where $A$ is the total aid budget; $A_{i}$ is the aid sent to country $i$ (it is a value function akin to a cost function) and $S_{i}^{R}$ and $S_{i}^{P}$ are the shadow prices of changing $R$ and 
$P$ in country $i$. If $A_{i}$ can be written as

$$
A_{i}=\left(1-\pi_{i}\right) \times b_{i}\left(S_{i}^{R}, S_{i}^{P}\right)
$$

where $b_{i}$ is homogeneous in the first degree in its arguments-so that doubling shadow prices doubles cost-then one may speak of solving the first stage. In other words, if the amount sent to country $i$ does not affect the price of changing repression and popular wealth there, then how much to send and the conditions to attach are independent problems. This however is not the present case. Repression may be influenced by varying the fixed component and the conditions which together as $A=F-\alpha R+\beta P$ give the cost. The cost of $P$ is arrived at in the same way. But the degree to which these instruments of policy influence repression depends (see section 3) on $\pi_{P R}$ which itself depends on the levels of $R$ and $P$ (the same may be said of $P$ ). Put differently, the levels of popular wealth and repression affect each others' costs by playing on the productivity of the instruments $\alpha, \beta$, and $F$. The optimal mix of these instruments in the production of one quantity (such as $R$ ) cannot be considered independently of the optimal mix for the other quantity $(P)$. In consequence, the shadow prices of changing repression and popular wealth are not constant, nor are they independent of $\pi$ (because $\pi$ is a function of $P$ and $R$ ). The donor who first allocates a sum to be spent on country $i$ and who intends to set the conditions later, acts without realizing that this sum will affect the shadow prices of $R$ and $P$. The effect of aid on a country's repression and on its popular wealth will depend on the level of aid and on the shape it takes. The potency of these instruments is a reflection of the shadow price of $R$ and $P$. How much to give and the conditions to attach cannot be separated, so that it makes no sense to set $A_{i}$ before attaching strings.

\section{Aid and Gastil's Indices of Repression}

The lesson from the last section is that an optimal policy of aid is not simple to prepare. The planner must have a good idea of how the regime in each candidate country stands (i.e. a knowledge of $\pi$ ) and how, in consequence, aid will find its way to repression and popular wealth. He must then use this knowledge to balance the benefit of aid to all countries. The rules for setting conditions are disturbingly 
ambiguous even in the case of a single potential recipient. When the crowd of claimants thickens, the planner cannot even look to two-stage budgeting to lighten the burden of his task. If, in view of these obstacles an ideal aid package is too much to ask of the planner, a proper notion of how his decisions will affect repression and popular wealth may not be. Many donors have experts, literally in the field, on whose grasp of the modalities of local politics they rely for answers to the questions "How will aid affect stability? Repression? Popular welfare?".

As shown in section 3 , the signs of the direct and cross effects of repression on stability can give some direction to the donor's groping for answers. Are there data from which estimates of these signs can be teased? The indices of repression collected by Gastil (1980) since 1973 for close to a hundred countries and the World Handbook of Political and Social Indicators (1983) come first to mind. Ideally, one would wish to regress a proxy for political stability on proxies for repression, income distribution and their cross-product, and deduce the signs of $\pi_{R}, \pi_{P}$ and $\pi_{P R}$ from the signs of the estimated coefficients. With different questions in mind Mbaka and Paul (1989) found that income inequality and the stability of a regime were negatively correlated. Their work is stimulating. Unfortunately, I know of no index of stability for any other than the 29 African countries in their sample. If for this practical reason, stability is treated as a latent variable, what is left to salvage?

Consider a specific example of the model of section 1. Suppose a regime survives if a latent measure of the propensity to survive $Z+\epsilon$ is greater than some number $\bar{Z}$. This propensity is the sum of a random component $\epsilon$ and a non-random component $Z$ which we assume is of the form:

$$
Z=a_{0}+a_{1} P+a_{2} P^{2}+a_{3} R+a_{4} R^{2}+a_{5} P \times R
$$

The goal is to estimate the coefficients $\left(a_{0}, a_{1}, a_{2}, a_{3}, a_{4}, a_{5}\right)$.Suppose the probability a regime stays in power is the probability that $Z+\epsilon$ exceeds $\bar{Z}$. Assuming that $\epsilon$ is generated by a standard normal distribution, this probability can be developed as follows:

$$
\begin{aligned}
\pi(P, R) & =\operatorname{Pr}(Z+\epsilon>\bar{Z}) \\
& =\operatorname{Pr}(\epsilon>\bar{Z}-Z) \\
& =1-\Phi(\bar{Z}-Z)
\end{aligned}
$$


where $\Phi$ is the standard normal cumulative density function. The oppressor now maximizes

$$
[1-\Phi(\bar{Z}-Z)] G+\lambda(Y-P-R-G)
$$

The foc's are

$$
\begin{aligned}
\left(a_{3}+2 a_{4} R+a_{5} P\right) \phi G & =\lambda \\
\left(a_{1}+2 a_{2} P+a_{5} R\right) \phi G & =\lambda \\
1-\Phi & =\lambda
\end{aligned}
$$

These conditions hold the implicit solution to the desired coefficients, but offer the econometrician no clue to how he should identify them in regressions of $R$ on $P$ and $G$. Nor does the reduced form of the above offer much hope. The non-linearity of the system makes it difficult to solve for $R, P$, and $G$ in terms of $Y$. This means that the reduced form representation of $R$ will not be the simple linear regression

$$
R=b_{0}+b_{1} Y
$$

and that in consequence $b_{1}$ (the standardized covariance between $Y$ and $R$ ) of which much has been written, has no obvious economic interpretation. In particular, $b_{1}$ cannot be construed as the derivative of $R$ w.r.t. $Y$. The early study by Dick (1974) and recent regressions of economic growth on Gastil's index of repression point to a negative relation between growth and repression (See Friedman 1988, Glahe and Vorhies 1989). They are quick to caution that correlation does not imply causation but cannot resist speculating that freedom may help economic performance. The present model casts doubt on such an interpretation and can as yet offer no theory to exploit the potential of the Gastil indeces. Perhaps correlations over time between different types of aid and repression are the best that can be hoped for.

\section{Summary and Conclusions}

Nations should know how their aid will be used, before they they give it. This paper has drawn attention to the thoughts that should be foremost in the mincls of the donor who contemplates giving aid to a repressive regime. These regimes control the distribution of wealth in their countries and repress their people with 
the object of holding power and enjoying a part of their country's riches. The donor may exert some influence on repression and popular wealth by attaching conditions to his aid which affect the relative prices of these quantities to the repressive ruler. However a subtle knowledge of how repression and popular wealth affect a regime's stability is needed to predict the effect that formal conditions have on aid.

Several points emerge from the analysis. Before aid finds its way to those who deserve it, the tyrant must first accept it and he will only do so under conditions that raise his utility. This is an obvious but unsavoury point which limits what aid can achieve. For example, under certain circumstances it may not be possible to lower repression and to increase popular wealth. Gifts in kind are no solution to this problem because they simply allow the tyrant to confiscate other more liquid assets which before he thought prudent to leave to his people. It was also argued that donors cannot set their aid budgets in two stages and that recently collected socio-political indicators such as the Gastil (1980) index of repression are probably of little use to the aid decision.

In spite of these obstacles much can be learned from from an economic analysis of the uses to which aid is put. The present model is such an attempt and has sought to set the tone of future discussions. A few of its many shortcomings should be mentioned. Risk aversion by both donor and recipient, and decisions over time were ignored. More seriously, the tyrant was assumed to have no knowledge of the donor's strategy or of the constraint his behaviour placed on the donor. Repressive rulers are in general, talented players of games. To ignore their dark skills is to leave a severe breach in the model, in urgent need of filling. 


\section{APPENDIX}

This part of the appendix derives the comparative statics used in sections 2 and 3. We will derive $R_{1+\alpha}$ and $P_{1+\alpha}$. The first order conditions for the dictator who maximizes subject to the aid constraint can be differentiated with respect to $1+\alpha$ (the price of repression) to give

$$
\left[\begin{array}{rrrr}
\pi_{R R} G & \pi_{R P} G & \pi_{R} & -(1+\alpha) \\
\pi_{P R} G & \pi_{P P} G & \pi_{P} & -(1-\beta) \\
\pi_{R} & \pi_{P} & 0 & -1 \\
-(1+\alpha) & -(1-\beta) & -1 & 0
\end{array}\right]\left[\begin{array}{l}
R_{1+\alpha} \\
P_{1+\alpha} \\
G_{1+\alpha} \\
\lambda_{1+\alpha}
\end{array}\right]=\left[\begin{array}{l}
\lambda \\
0 \\
0 \\
R
\end{array}\right]
$$

By Cramer's rule we can solve for $R_{1+\alpha}$

$$
R_{1+\alpha}=\operatorname{det}\left[\begin{array}{rrrr}
\lambda & \pi_{R P} G & \pi_{R} & -(1+\alpha) \\
0 & \pi_{P P} G & \pi_{P} & -(1-\beta) \\
0 & \pi_{P} & 0 & -1 \\
R & -(1-\beta) & -1 & 0
\end{array}\right] / \Delta
$$

where $\Delta$ is the determinant of the bordered Hessian derived from the second-order conditions. The above can be broken into the sum of substitution and income effects. The substitution effect is

$$
\frac{\lambda}{\Delta}\left[\left(-\pi_{P P} G+2 \pi_{P}(1-\beta)\right]\right.
$$

The income effect is

$$
R \times\left(-\pi_{P} \pi_{R P} G+\pi_{R} \pi_{P P} G-\pi R \pi_{P}(1-\beta)+(1+\alpha) \pi_{P}^{2}\right) / \Delta
$$

but the last two terms sum to zero by the f.o.c.'s so that the income effect reduces to

$$
R \times \pi_{R} G\left[\pi_{P P}-\left(\frac{1-\beta}{1+\alpha}\right) \pi_{R P}\right] / \Delta
$$

That this is the income effect can be proved if comparative statics are done w.r.t. $Y$. When there is no aid, this income effect reduces to the income effect studied in section 2. The derivative of popular wealth w.r.t. the price of repression can be similarly derived. 
It now remains to show what combination of $\alpha$ and $F$ can be used to reduce repression and to increase popular wealth. If $\alpha$ and $F$ change in a manner that reduces repression, then

$$
R_{1+\alpha} d \alpha+R_{Y} d F<0
$$

If at the same time popular wealth is to rise, then

$$
P_{1+\alpha} d \alpha+P_{Y} d F>0
$$

combining the above euquations gives the implicit bounds within which $\alpha$ and $F$ may change:

$$
-\frac{P_{1+\alpha}}{P_{Y+F}}<\frac{d F}{d \alpha}<-\frac{R_{1+\alpha}}{R_{Y+F}}
$$

\section{BIBLIOGRAPHY}

Bauer, L. "Black Africa: Free or Oppressed?" Freedom, Democracy and Economic Welfare, Ed. M. Walker, Vancouver: The Fraser Institute, 1988.

Becker, G.S. Economic Theory. New York: Alfred A. Knopf, 1970.

DeJong, A. Stalin and the Shaping of the Soviet Union. Glasgow: William Collins, Sons and Co., 1986.

Dick, W. G. (1974) "Authoritarian Versus Nonauthoritarian Approaches to Economic Development." Journal of Political Economy, 82: 817-827

Dudley, L. and C. Montmarquette (1976) "A Model of the Supply of Bilateral Foreign Aid." American Economic Review 66: 132-142

Friedman, M. "A Statistical Note on the Gastil-Wright Survey of Freedom." Freedom, Democracy and Economic Welfare, Ed. M. Walker, Vancouver: The Fraser Institute, 1988.

Gastil, R. Freedom in the World, Political Rights and Civil Liberty. New York, N.Y.: Freedom House, 1980.

Glahe, F. and F. Vorhies (1989) "Religion, Liberty and Economic Development: An Empirical Investigation." Public Choice 62: 201-215

Korn, D.A. Ethiopia the United States and the Soviet Union. Carbondale, Illinois: Southern Illinois University Press, 1986.

Mbaka, J and C. Paul (1989) "Political Instability in Africa: A Rent-Seeking Approach." Public Choice 63: 63-72 
McGuire, M.F. and V.W. Ruttan (1989) "Lost Directions: U.S. Foreign Assistance Policy Since New Directions" Working paper Economic Development Center, University of Minnesota.

McNeill, W.H. The Rise of the West. Chicago: University of Chicago Press, 1958.

Palda, F. (1989) "A Note on the Distribution of Income in Totalitarian States" unpublised manuscript, University of Chicago.

Parry, I.W.H. (1989) "A Note on Predicting the Pace of Reform in Totalitarian States." unpublished manuscript, University of Chicago.

Roemer, J.E. (1985) "Rationalizing Revolutionary Ideology." Econometrica 53: 85-108

Taylor, C. and D. Jodice World Handbook of Political and Social Indicators, Vol. I. New Haven: Yale University Press, 1983.

Usher, D. and M. Engineer (1987), "The Distribution of Income in a Despotic Society." Public Choice 54: 261-276

Weck-Hanneman, H. and F. Schneider (1988), "Determinants of Foreign Aid Under Alternative Institutional Arrangements" working paper \#8803, Johannes Kepler University of Linz.

Wintrobe, R. (1989) "The Tinpot and the Totalitarian: A Simple Economic Theory of Dictatorship" Forthcoming in American Political Science Review. 